\title{
Strategi Pemasaran Jamur Tiram Di Kabupaten Probolinggo
}

\author{
Novita Lidyana1, Dyah Ayu Perwitasari² \\ ${ }^{1}$ Fakultas Pertanian Universitas Panca Marga Probolinggo \\ 2.Fakultas Ekonomi Universitas Panca Marga Probolinggo \\ email: novitalidyana2019@gmail.com ${ }^{1}$, dyahayu@upm.ac.id ${ }^{2}$,
}

Kata kunci: strategi, pemasaran,jamur tiram

Keywords: strategy, marketing, oyster mushroom

\begin{tabular}{l}
\hline ABSTRAK \\
\hline Penelitian bertujuan untuk mengetahui kondisi kekuatan, kelemahan, \\
peluang serta ancaman yang dialami oleh petani jamur tiram di \\
Kabupaten Probolinggo dalam memasarkan produknya. Kabupaten \\
Probolinggo menjadi tempat penelitian yang terpilih secara purposive. Di \\
Kabupaten Probolinggo terdapat petani jamur tiram yang tersebar di \\
beberapa Kecamatan. Jumlah reponden yang digunakan dalam \\
penelitian ini sebanyak 60 petani yang berusaha tani jamur tiram. \\
Penelitian ini menggunakan metode SWOT. Pada penelitian ini yang \\
menjadi kekuatan usaha dalam memasarkan hasil panen jamur adalah \\
umur petani, tenaga kerja yang dimiliki. Kelamahan yang dihadapi \\
adalah kesulitan dalam pemasaran, jamur tiram tidak bertahan lama \\
serta terbatasnya modal bagi petani. Untuk peluang usaha adalah \\
permintaan jamur yang terus meningkat serta adanya diversifikasi \\
produk olahan berbahan dasar jamur. Untuk mengatasi hal tersebut \\
maka dilakukan strategi SO yaitu Strenghts - Opportunities, kekuatan \\
yang dimiliki dapat digunakan untuk memanfaatkan peluang yang ada \\
dengan adanya permintaan jamur serta memanfaatkan pasar yakni \\
dengan harga yang stabil serta memberikan pelatihan diversifikasi \\
produk olahan berbahan dasar jamur
\end{tabular}

Strategi Pemasaran Jamur Tiram di Kabupaten Probolinggo

https://doi.org/10.35457/xxx

(C) 2019 Akuntabilitas: Jurnal Ilmu-Ilmu Ekonomi. Semua hak cipta dilindungi undang-undang 


\section{ABSTRACT}

Novita Lidyana, Dyah Ayu Perwitasari (2021). Strategi Pemasaran Jamur Tiram Di Kabupaten Probolinggo. Akuntabilitas : Jurnal Ilmiah IlmuIlmu Ekonomi , 14 (2), 10-20
Research aims to find out the conditions of strength, weakness, opportunity and threat experienced by oyster mushroom farmers in Probolinggo Regency in marketing their products. Probolinggo regency became a purposively selected research site. In Probolinggo Regency there are oyster mushroom farmers scattered in several sub-districts. The number of respondents used in this study as many as 60 farmers who tried to farm oyster mushrooms. This research uses swot methods. In this study, the strength of business in marketing mushroom crops is the age of farmers, the labor owned. The dark encounter is the difficulty in marketing, oyster mushrooms do not last long and limited capital for farmers. For business opportunities are the growing demand for mushrooms and the diversification of processed products made from mushrooms. To overcome this, so strategy is done, namely Strenghts - Opportunities, the power that is owned can be used to take advantage of existing opportunities with the demand for mushrooms and take advantage of the market at a stable price and provide training in diversifying processed products made from mushrooms.

\section{PENDAHULUAN}

Sumber bahan makanan yang saat ini mulai digrandrungi adalah jamur tiram. Jamur tiram dengan istilah mushroom adalah makanan berprotein yang cukup tinggi. Selain itu banyak olahan makanan yang dapat dihasilkan berbahan dasar jamur tiram.

Di Kabupaten Probolinggo budidaya jamur tiram mulai banyak untuk dikembangkan (Lidyana et al., 2021). Hal ini disebabkan oleh ketersediaan bahan baku baglog/media jamur mudah diperoleh serta cara perawatan jamur tiram dipandang lebih mudah dari pada usaha budidaya tanaman holtikultura lainnya. Namun, dalam menjalankan usaha budidaya jamur tiram, bukan hanya memperhatikan pada segi ketersedian bahan baku dan perawatan dalam budidaya jamur tiram, tetapi juga harus memperhatikan pemasaran yang tepat. Jika tidak diperhatikan serta mencari strategi yang tepat dalam pemasaran, maka jamur yang diproduksi tidak maksimal dalam penjualan. Dan akan berakibat petani akan mengalami bahkan kegagalan dalam berusahatani jamur tiram tersebut.

Strategi pemasaran adalah cara untuk mendapatkan keunggulan bersaing yang berkelanjutan bagi perusahaan yang memproduksi barang atau jasa. Strategi pemasaran dapat dikatakan sebagai salah satu dasar penyusunan rencana perusahaan secara keseluruhan. Mengingat luasnya cakupan permasalahan di dalam perusahaan, maka diperlukan suatu perencanaan yang komprehensif sebagai pedoman kegiatan berbagai departemen dalam perusahaan (Wibowo et al., 2015).

Strategi Pemasaran Jamur Tiram di Kabupaten Probolinggo

https://doi.org/10.35457/xxx

(c) 2019 Akuntabilitas: Jurnal Ilmu-Ilmu Ekonomi. Semua hak cipta dilindungi undang-undang 
Pemasaran membutuhkan perhatian serius dari semua perusahaan komersial. Apalagi dalam proses penentuan strategi pemasaran harus benar-benar matang, agar strategi pemasaran yang dipilih dapat menembus pasar. Apalagi dalam persaingan yang semakin ketat saat ini, apakah dapat merebut pangsa pasar akan mempengaruhi kelangsungan hidup perusahaan itu sendiri. Tak terkecuali para petani jamur di Kabupaten Probolinggo. Salah satu posisi manajemen memang perlu merumuskan strategi pemasaran yang tepat sebagai tugas pertama menghadapi persaingan untuk mengembangkan pasar. Berdasarkan latar belakang di atas, penelitian ini berjudul Strategi Pemasaran Jamur Tiram Kabupaten Probolinggo.

\section{METODE PENELITIAN}

Metode Penelitian ini dilakukan secara sengaja di Kabupaten Probolinggo. Di Kabupaten Probolinggo terdapat 60 petani budidaya jamur tiram di beberapa kecamatan.

Menurut daftar pertanyaan yang telah disiapkan, data primer dikumpulkan dari petani sampel melalui wawancara. Data sekunder diperoleh dari lembaga terkait, misal Balai Penyuluhan Pertanian Daerah (BPP) dan Badan Pusat Statistik (BPS) Kabupaten Probolinggo.

Metode yang digunakan dalam memecahkan masalah penelitian adalah analisis deskriptif dan analisis SWOT. Pembuatan matriks SWOT dengan mengikuti langkahlangkah di bawah ini:

1. Pengumpulan data faktor internal dan eksternal yang dilakukan petani dalam memasaran jamur di Kabupaten Probolinggo

2. Penentuan rangking (rank), bobot dan tahapan penilaian dari masing-masing faktor yang dipilih

3. Penentuan matriks posisi

4. Gunakan matriks SW untuk merumuskan tahapan faktor strategis

\section{HASIL DAN PEMBAHASAN}

Strategi Pemasaran Jamur Tiram di Kabupaten Probolinggo https://doi.org/10.35457/xxx

(C) 2019 Akuntabilitas: Jurnal Ilmu-Ilmu Ekonomi. Semua hak cipta dilindungi undang-undang 


\section{Kekuatan dalam Memasarkan Usaha Jamur Tiram Di Kabupaten Probolinggo}

\section{Umur Petani}

Usia petani jamur tiram di Kabupaten Probilinggo sangat banyak terdistribusi pada kelompok usia 35- 44 tahun ataupun kelompok usia sedang (L. Novita, P. D. Ayu, 2021). Perihal ini bisa disimpulkan kalau pada umur- umur tersebut ialah usia produktif yang membolehkan seorang buat berupaya bekerja secara optimal dalam penuhi kebutuhan hidup rumah tangga. Dengan unur produktif membolehkan petani buat terus belajar serta berinovasi dalam budidaya jamur, sehingga usia petani jamur menjadikan kekuatan dalam proses pengembangan budidaya jamur tiram.

\section{Tenaga Kerja yang dimiliki}

Penggunaan tenaga kerja berasal dari tenaga kerja keluarga, dimana tenaga kerja tersebut banyak dilakukan oleh, istri, anak bahkan cucu yang membantu dalam proses pemeliharan dalam budidaya jamur tiram. Dalam pemeliharaan jamur tiram ini tidak memerlukan keahlian khusus, sehingga mudah dalam pelaksaanaannya. Hal ini membuat tenaga kerja menjadi kekuatan dalam usaha budidaya jamur tiram.

\section{Harga jual jamur}

Harga jual jamur di pasaran berkisar antara Rp.14.000 sampai Rp. 21.000 per kg pada tingkat pengecer. Harga di pasaran relatif lebih stabil, sehingga harga jamur ini menjadikan penyemangat bagi petani jamur dalam memasarkan hasil panennya setiap hari. Apalagi dari hasil pengamatan peneliti, ketersediaan jamur di pasar jumlah masih sedikit, sehingga belum memenuhi kebutuhan pasar di Kabupaten Probolinggo.

\section{Kelemahan dalam Usaha Memasarkan Jamur Tiram Di Kabupaten Probolinggo}

\section{Pemasaran produk}

Strategi Pemasaran Jamur Tiram di Kabupaten Probolinggo 
Dalam memasarkan jamur tiram, petani mengandalkan saluran pemasaran. Dimana saluran pemasaran yang digunakan adalah dari petani kemudian dijual kepada pengecer dari pengecer dijual pada konsumen akhir. Petani kesulitan untuk menjual sendiri hasil panennya. Hasil panen jamur $3.253 \mathrm{~kg}$ selama 1 proses produksi (3 bulan) atau $39 \mathrm{~kg} /$ hari. Dengan jumlah panen yang banyak membuat petani kesulitan untuk menjual sendiri hasil panen.

\section{Jamur tiram yang tidak bertahan lama}

Hasil panen produk jamur tiram yang dihasilkan oleh petani jamur di Kabupaten Probolinggo mempunyai produk yang memilki kualitas yang baik namun daya simpan dari jamur hanya 2 hingga 3 hari saja. Perihal tersebut disebabkan, kondisi jamur tiram memiliki kandungan air yang tinggi, sehingga membuat jamur menjadi cepat basah dan mudah membusuk.

\section{Ketersediaan modal bagi petani}

Modal merupakan hal penting dalam berusahatani. Demikian halnya dengan petani. Petani jamur tiram mengeluhkan kekurangan modal dalam mengembangkan usaha tani jamur tiram. Petani menginginkan adanya mitra dalam memberikan bantuan/pinjaman modal. Dari hasil wawancara, hanya beberapa saja yang menjadi anak asuh oleh perusahaan swasta, sehingga petani tersebut bisa tetap eksis dalam menjalankan usaha. Namun petani-petani lainnya kesulitan. Sehingga ini menjadi kelemahan bagi petani untuk meneruskan usahanya.

\section{Peluang dalam Usaha memasarkan Jamur Di Kabupaten Probolinggo}

\section{Permintaan jamur terus meningkat}

Jamur tiram ialah bahan makanan yang digemari dari bermacam golongan disebabkan harga beli yang masih bisa terjangkau. Ini jadi kesempatan untuk petani jamur. Permintaan akan jamur selalu meningkat setiap tahunnya. Sehingga membuka peluang bagi petani untuk terus membudidayakan jamur.

\section{Diversifikasi produk olahan berbahan dasar jamur}

Akhir-akhir ini masyarakat memiliki selera untuk konsumsi jamur tiram. Hal ini

Strategi Pemasaran Jamur Tiram di Kabupaten Probolinggo 
membuka peluang untuk petani jamur tiram di Kabupaten Probolinggo. Jmaur tiram ini memiliki kandungan nilai gizi bagi tubuh, serta memiliki rasa yang lezat dan dapat diolah menjadi bermacam-macam jenis produk makanan. Contoh olahan jamur tiram adalah jamur krispy, botok jamur, jate jamur, nasi bakar jamur dan lainnya.

\section{Ancaman dalam Usaha memasarkan Jamur Tiram Di Kabupaten Probolinggo}

\section{Persaingan antar petani jamur}

Keberadaan pesaing menjadi ancaman bagi petani. Pesaing yang dimaksudkan ini adalah petani yang memiliki usaha budidaya jamur yang berskala besar. Sehingga kondisi ini, ketersediaan jamur dikuasai oleh petani yang berskala kecil.

\section{Perubahan Cuaca}

Cuaca menjadi hal penting dalam budidaya jamur. Jamur jenis tanaman yang bergantung pada perubahan cuaca. Kabupaten Probolinggo merupakan wilayah dataran rendah yang cenderung cuaca panas. Saat musim kemarau, jika petani tidak pandai dalam mengatur suhu dalam kumbung, maka produktifitas jamur semakin menurun. Ini menjadi ancaman bagi petani dalam memperhatikan perubahan cuaca.

\section{Strategi Pemasaran Usaha Tamur Tiram di Kabupaten Probolinggo}

Kekuatan dan kelemahan menjadi faktor internal dalam usaha jamur tiram yang akan dimasukkan kedalam matriks di bawah ini:

Tabel 1. Matriks Internal Factor Analysis Summary (IFAS)

\begin{tabular}{|c|c|c|c|c|}
\hline & IFAS & Bobot & Rating & Skor \\
\hline \multicolumn{5}{|c|}{ Kekuatan } \\
\hline 1 & Umur Petani & 21,38 & 4 & 51.71 \\
\hline 2 & Tenaga Kerja yang dimiliki & 10,04 & 3 & 32,52 \\
\hline 3 & Harga Jual jamur tiram & 15,39 & 4 & 36,32 \\
\hline \multicolumn{5}{|c|}{ Kelemahan } \\
\hline 1 & Pemasaran jamur tiram & 16,67 & 2 & 40,01 \\
\hline 2 & $\begin{array}{l}\text { Jamur tiram yang tidak bertahan } \\
\text { lama }\end{array}$ & 22,42 & 4 & 75,23 \\
\hline
\end{tabular}

Strategi Pemasaran Jamur Tiram di Kabupaten Probolinggo 


\begin{tabular}{|l|l|c|c|c|}
\hline 3 & Modal yang dimilki petani & 13,38 & 3 & 33,24 \\
\hline Total & $\mathbf{1 0 0}$ & $\mathbf{2 1}$ & $\mathbf{2 7 9}, \mathbf{2 3}$ \\
\hline
\end{tabular}

Sumber: diolah dari data primer

Pada tabel di atas diperoleh faktor internal, bahwa pada kekuatan skor tertinggi ada pada umur petani. Sedangkan skor tertinggi pada aspek kelemahan adalah jamur tiram yang tidak tahan lama.

Faktor eksternal adalah peluang dan ancaman dalam usaha memasarkan jamur dengan memberikan pembobotan serta rating pada tabel di bawah ini:.

Tabel 2. Matriks Ekternal Factor Analysis Summary (EFAS)

\begin{tabular}{|c|c|c|c|c|}
\hline & EFAS & Bobot & Rating & Skor \\
\hline \multicolumn{5}{|c|}{ Peluang } \\
\hline 1 & $\begin{array}{l}\text { Permintaan jamur terus } \\
\text { meningkat }\end{array}$ & 27,67 & 4 & 59,78 \\
\hline 2 & $\begin{array}{l}\text { Diversifikasi produk olahan } \\
\text { berbahan dasar jamur tiram }\end{array}$ & 27,67 & 4 & 59,78 \\
\hline \multicolumn{5}{|c|}{ Ancaman } \\
\hline 1 & Persaingan antar petani jamur & 27,67 & 4 & 120,97 \\
\hline 2 & Perubahan cuaca & 16,99 & 2 & 73,25 \\
\hline \multicolumn{2}{|c|}{ Total } & 100 & 14 & 313,51 \\
\hline
\end{tabular}

Sumber: diolah dari data prime

Pada faktor strategi eksternal, peluang permintaan jamur terus meningkat serta diversifikasi produk olahan jmaur tiram memiliki peluang yang sama besar. Sedangkan faktor strategi pada ancaman nilai tertinggi adalah persaingan antar petani jamur.

Kedua faktor ekternal dan internal jika digabungkan maka :

Tabel 3. Menggabungkan Matriks IFAS dan EFAS

\begin{tabular}{|c|c|c|c|c|}
\hline & IFAS & Bobot & Rating & Skor \\
\hline \multicolumn{5}{|c|}{ Kekuatan } \\
\hline 1 & Umur Petani & 21,38 & 4 & 51.71 \\
\hline 2 & Tenaga Kerja yang dimiliki & 10,04 & 3 & 32,52 \\
\hline 3 & Harga Jual jamur tiram & 15,39 & 4 & 36,32 \\
\hline
\end{tabular}

Strategi Pemasaran Jamur Tiram di Kabupaten Probolinggo https://doi.org/10.35457/xxx

(C) 2019 Akuntabilitas: Jurnal Ilmu-Ilmu Ekonomi. Semua hak cipta dilindungi undang-undang 


\begin{tabular}{|c|c|c|c|c|}
\hline Total & & 61 & 11 & 120,85 \\
\hline \multicolumn{5}{|c|}{ Kelemahan } \\
\hline 1 & Pemasaran jamur tiram & 16,67 & 2 & 40,01 \\
\hline 2 & $\begin{array}{l}\text { Jamur tiram yang tidak bertahan } \\
\text { lama }\end{array}$ & 22,42 & 4 & 75,23 \\
\hline 3 & Modal yang dimilki petani & 13,38 & 3 & 33,24 \\
\hline \multicolumn{2}{|l|}{ Total } & 63 & 9 & 108,48 \\
\hline \multicolumn{4}{|c|}{ Selisih kekuatan dan kelemahan dalam memasarkan jamur } & 11,87 \\
\hline & EFAS & Bobot & Rating & Skor \\
\hline \multicolumn{5}{|c|}{ Peluang } \\
\hline 1 & $\begin{array}{l}\text { Permintaan jamur terus } \\
\text { meningkat }\end{array}$ & 27,67 & 4 & 59,78 \\
\hline 2 & $\begin{array}{l}\text { Diversifikasi produk olahan } \\
\text { berbahan dasar jamur tiram }\end{array}$ & 27,67 & 4 & 59,78 \\
\hline \multicolumn{2}{|l|}{ Total } & 61 & 8 & 119,56 \\
\hline \multicolumn{5}{|c|}{ Ancaman } \\
\hline 1 & Persaingan antar petani jamur & 27,67 & 4 & 120,97 \\
\hline 2 & Perubahan cuaca & 16,99 & 2 & 73,25 \\
\hline \multicolumn{2}{|l|}{ Total } & 63 & 6 & 101,22 \\
\hline \multicolumn{4}{|c|}{ Selisih peluang dan ancaman dalam memasarkan jamur } & 18,34 \\
\hline
\end{tabular}

Sumber: diolah dari data primer

Dari data di atas dapat ditarik kesimpulan bahwa dalam faktor internal, faktor kekuatan memiliki selisih 11,87 dari faktor kelemahan. Hal ini menandakan bahwa adanya kekuatan dalam pemasaran jamur tiram di Kabupaten Probolinggo. Sedangkam pada segi faktor eksternal nilai peluang lebih besar

dari pada ancaman. Dimana dihasilkan selisih sebesar 18,34. Hal ini berarti peluang untuk memasarkan jamur tiram lebih tinggi dari pada ancaman yang terjadi pada Kabupaten Probolinggo. 
Posisi strategis dalam pemasaran jamur tiram, ada pada gambar di bawah ini:

III

Mendukung Strategi

Memanfaatkan peluang
Berbagai Peluang

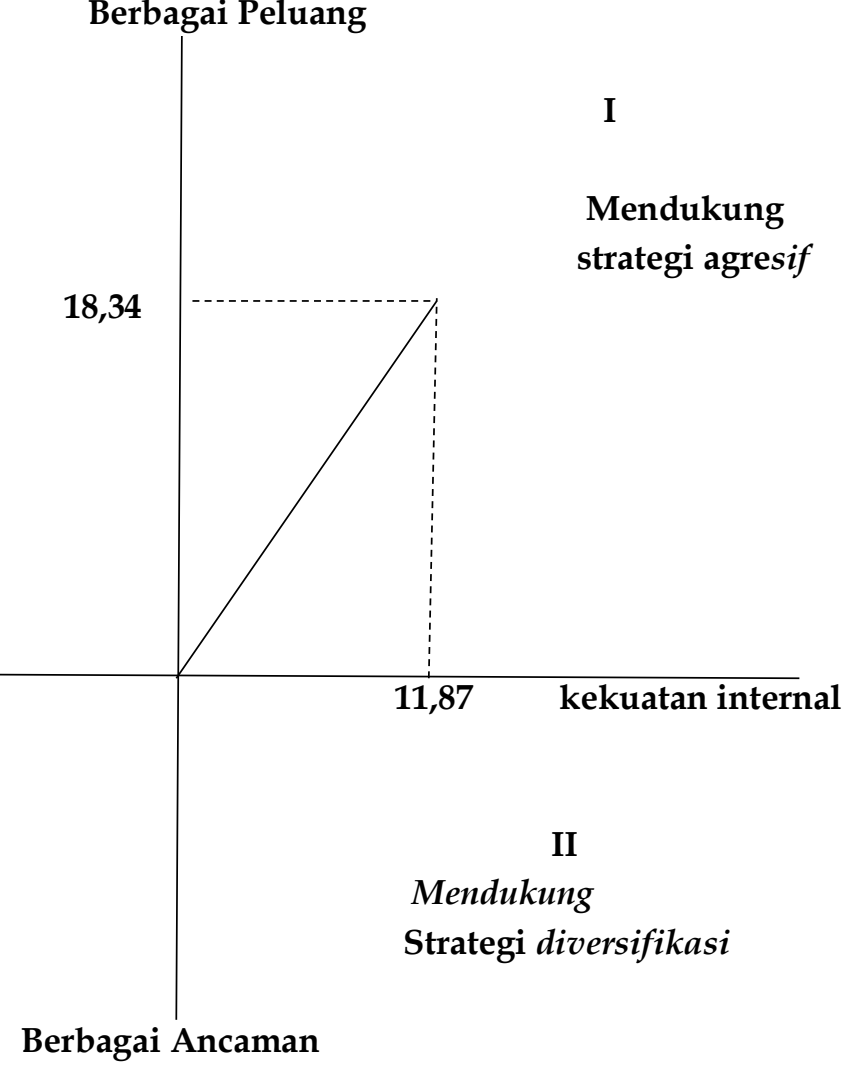

\section{Gambar 1. Posisi Strategis Pemasaran Jamur}

Dari hasil matriks di atas, maka analisis SWOT dalam faktor-faktor strategis dalam pemasaran jamur tiram di Kabupaten Probolinggo sebagai berikut:

Dari hasil matriks di atas, maka analisis SWOT dalam faktor-faktor strategis dalam pemasaran jamur tiram di Kabupaten Probolinggo sebagai berikut:

\begin{tabular}{|c|c|c|}
\hline INTERNAL & $\begin{array}{l}\text { KEKUATAN (S) } \\
\text { 1. Umur Petani (S1) } \\
\text { 2. PenggunaanTenaga } \\
\text { Kerja yang dimiliki } \\
\text { (S2) } \\
\text { 3. Tingkat harga jual } \\
\text { jamur (S3) }\end{array}$ & $\begin{array}{l}\text { KELEMAHAN (W) } \\
\text { 1. Pemasaran jamur } \\
\text { tiram (W1) } \\
\text { 2. Jamur tiram tidak } \\
\text { bertahan lama (W2) } \\
\text { 3. Ketersediaan modal } \\
\text { (W3) }\end{array}$ \\
\hline $\begin{array}{l}\text { PELUANG (O) } \\
\text { 1. Permintaan }\end{array}$ & 1. Pemanfaatan & 1. Memberikan bantuar \\
\hline
\end{tabular}

Strategi Pemasaran Jamur Tiram di Kabupaten Probolinggo https://doi.org/10.35457/xxx

(C) 2019 Akuntabilitas: Jurnal Ilmu-Ilmu Ekonomi. Semua hak cipta dilindungi undang-undang 


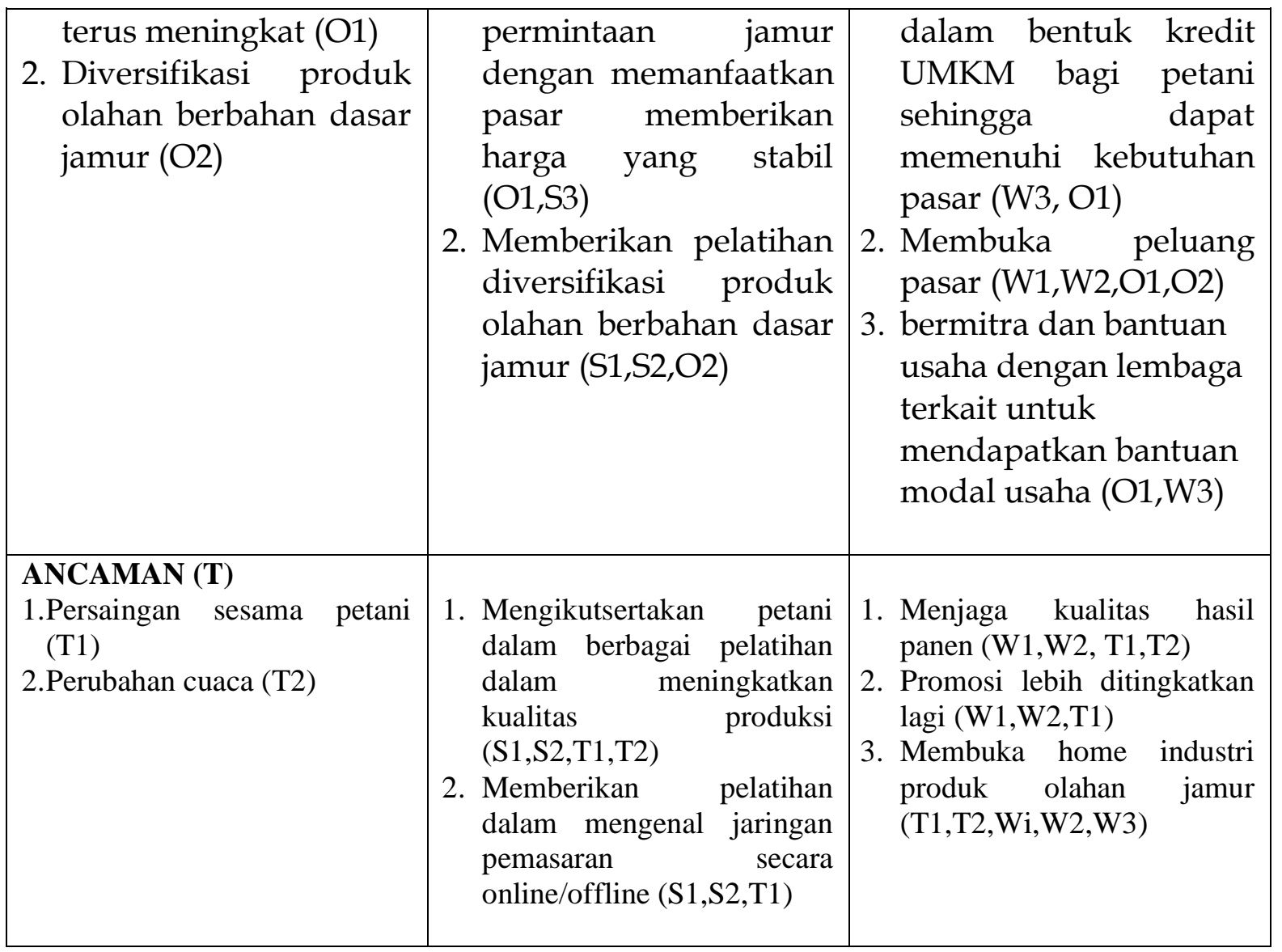

Strategi yang tepat digunakan untuk strategi pemasaran jamur tiram di kabupaten Probolinggo berada pada Kuadran I yaitu strategi fokus pada SO (Strengths - Opportunities).Pada strategi ini kekuatan yang yang ada dijadikan sebagai peluang yaitu :

1. Pemanfaatan permintaan jamur dengan memanfaatkan pasar yaitu dengan harga yang stabil $(\mathrm{O} 1, \mathrm{~S} 3)$

Permintaan pasar akan ketersediaan jamur membuka peluang bagi petani untuk terus meningkatkan hasil produksi/panen dengan maksimal. Hal ini akan menyebabkan harga yang akan tetap stabil, karena ketersediaan atas permintaan konsumen dapat terpenuhi

2. Memberikan pelatihan diversifikasi produk olahan berbahan dasar jamur (S1,S2,O2)

Umur Petani jamur yang yang berada pada kisaran umur sedang, menungkinkan untuk terus berinovasi, sehingga dengan adanya pelatihan-pelatihan akan membuat petani menjadi lebih mahir dalam pengelolaan jamur tiram. Serta dengan adanya diversifikasi produk olahan jamur memungkinkan petani menjual jamur dalam bentuk olahan. Hal ini akan menambah pendapatan petani jamur.

Strategi Pemasaran Jamur Tiram di Kabupaten Probolinggo 


\section{KESIMPULAN}

1. Dalam pemasaran jamur tiram di Kabupaten Probolinggo, kekuatan, kelemahan, serta ancaman yang dihadapi oleh petani dalam memasarkan jamur.

2. Beberapa strategi yang digunakan dalam meningkatkan pemasaran pada jamur tiram di Kabupaten Probolinggo dengan berfokus pada stategi agresif yakni strategi dengan menggunakan kekuatan dan pemanfaatan peluang (Strengths - Opportunities) yakni dengan :

a. Pemanfaatan permintaan jamur dengan memanfaatkan pasar yakni dengan harga yang stabil

b. Memberikan pelatihan dalam diversifikasi produk berbahan dasar jamur

\section{DAFTAR PUSTAKA}

L. Novita, P. D. Ayu, M. (2021). Faktor-Faktor Yang Mempengaruhi Pendapatan Usahatani Jamur Timur Di Kabupaten Probolinggo. 7(1), 4-20.

Lidyana, N., Perwitasari, D. A., \& Rustianawati, M. (2021). Revenue And Marketing Channel of Oyster Mushroom In Probolinggo District. Wiga : Jurnal Penelitian Ilmu Ekonomi, 11(1), 3138. https://doi.org/10.30741/wiga.v11i1.576

Wibowo, D. H., Arifin, Z., \& Sunarti. (2015). Strategi dan Program Pemasaran. Jurnal Administrasi Bisnis (JAB), 29(1), 59-66.

Cahyana, Y. A. 1997. Pembibitan dan Budidaya Jamur Tiram Putih. Papas Sinar Sinanti. Jakarta.

Dahl, Dale C. and Hammond J.W,1992. Market and Proce Analysis. The Agriculture Industries. Mc. Graww-Hill Book Company, Inc.

Dania. 1998. Teknik Budidaya Jamur Tiram Putih. Penebar Swadaya.

Direktorat Jendral Bina Produksi 2007. Statistik Produksi Holtikultura. Pusat Data dan Informasi. Jakarta.

Kohls, R.L and J.N.Uhl,1985. Marketing of Agriculture Product. Seventh Edition.

Purdue University. Maccmillan Publishing Company. New York.

Kotler, P. 2002. Manajemen Pemasaran. Edisi Milenium. Prenhallindo.

Muchrodi. 2001. Jamur Tiram Putih. Penebar Swadaya. Jakarta .

Rahmat, Suryani dan Nurhidayat. 2011. Untung Besar Dari Bisnis Jamur Tiram. Agromedia Pustaka: Jakarta

Strategi Pemasaran Jamur Tiram di Kabupaten Probolinggo

https://doi.org/10.35457/xxx

(C) 2019 Akuntabilitas: Jurnal Ilmu-Ilmu Ekonomi. Semua hak cipta dilindungi undang-undang 

Judul artikel

https://doi.org/10.35457/xxx

(C) 2019 Akuntabilitas: Jurnal Ilmu-Ilmu Ekonomi. Semua hak cipta dilindungi undang-undang 